\title{
Sistem informasi biaya balik nama kendaraan bermotor melalui Aplikasi sms gateway
}

\author{
Ade Irma Suryani ${ }^{1}$, Sri Restu Ningsih ${ }^{2}$, Hikko Razaki $^{3}$ \\ ${ }^{1,2,3}$ Sistem Informasi, STMIK Indonesia Padang
}

Jl. Khatib Sulaiman Dalam No.1 Kecamatan Padang Utara 25137 Telp (0751) 7058325

E-mail: 19adeirma@stmikindonesia.ac.id, ${ }^{2}$ srirestuningsih@yahoo.co.id, ${ }^{3}$ hikko@yahoo.com

\begin{abstract}
Abstrak
Tujuan dari penelitian ini adalah untuk meningkatkan pelayanan publik dan efektifitas kinerja di kantor SAMSAT Kota Padang dengan cara memberikan informasi biaya BBNKB kepada masyarakat yang akan melakukan transaksi balik nama. Biaya Balik Nama Kendaraan Bermotor (BBNKB) termasuk salah satu transaksi yang paling banyak dilakukan pada kantor SAMSAT Padang. Saat ini media pendukung untuk biaya balik nama kendaraan belum ada, sehingga orang wajib pajak tidak mengetahui berapa biaya yang harus mereka bayar. Untuk menyelesaikan masalah tersebut perlu dikembangkan sebuah Sistem Informasi Biaya Balik Nama Kendaraan Bermotor (BBNKB) berbasis SMS Gateway. Pengembangan software berbasis SDLC dengan metode XP (Extreme Programming). Sistem ini dikembangkan dengan bahasa pemrograman VB.Net, dan database MySQL sebagai menyimpan data serta Gammu sebagai konfigurasi SMS Gateway. Hasil dari penelitian ini adalah sebuah aplikasi yang dapat digunakan bagi wajib pajak agar mengetahui jumlah biaya balik nama kendaraan bermotor, yang dapat meningkatkan efesiensi kerja pada kantor SAMSAT kota Padang.
\end{abstract}

Kata kunci: SMS Gateway, SAMSAT, Extreme Programming

\begin{abstract}
The purpose of this research is to improve public services and effectiveness of performance at the SAMSAT office in the city of Padang by providing information on BBNKB costs to people who will conduct transactions behind the name. The cost of transferring motor vehicle names (BBNKB) is one of the most widely carried out transactions at the SAMSAT Padang office. At present there are no supporting media for the return of vehicle names, so that taxpayers do not know how much they must pay. To solve this problem, it is necessary to develop an Motorbike Name Return Fee Information System (BBNKB) based on SMS Gateway. SDLC based software development with XP (Extreme Programming) method. This system was developed with the $V B . N e t$ programming language, and the MySQL database as a data store and Gammu as an SMS Gateway configuration. The results of this study are an application that can be used for taxpayers to find out the amount of return costs for motorized vehicles, which can improve work efficiency at the SAMSAT office in the city of Padang.
\end{abstract}

Keywords: SMS Gateway, SAMSAT, Extreme Programming

\section{Pendahuluan}

Sistem Administrasi Manunggal Satu Atap (SAMSAT) sebagai suatu sistem administrasi yang dibentuk untuk memperlancar dan mempercepat pelayanan kepentingan masyarakat yang kegiatannya diselenggarakan dalam satu kantor. SAMSAT merupakan suatu sistem kerjasama secara terpadu antara Polri, Dinas Pendapatan Daerah, dan PT. Jasa Raharja (Persero) [1]. Sudah banyak fitur-fitur pelayanan yang disediakan oleh SAMSAT Kota Padang untuk saat ini, seperti pelayanan informasi Pajak Kendaraan Bermotor (PKB) melalui aplikasi android, pelayanan informasi PKB melalui web dan ada juga pelayanan informasi PKB melalui SMS. Tapi itu hanya sekedar untuk informasi pajak saja, sedangkan untuk media informasi Biaya Balik Nama Kendaraan Bermotor (BBNKB) belum ada sama sekali fitur pelayanan yang di 
bangun oleh pihak SAMSA di kota Padang. Padahal bukan hanya PKB saja, BBNKB juga salah satu transaksi yang ada di kantor SAMSAT Padang.

Wajib Pajak butuh informasi berapa biaya balik nama yang harus dikeluarkan saat sebelum membayar. Terkadang wajib pajak mengeluh karena uang yang tidak cukup saat akan membayar ke kasir, tidak tahu berapa biaya balik nama yang harus dibayarkan, dan mereka hanya mengetahui dengan pasti uang pajak saja, sedangkan untuk BBNKB sama sekali mereka tidak tahu, maka mengakibatkan kurangnya minat Wajib Pajak untuk melakukan balik nama, sehingga kinerja SAMSAT menjadi tidak efektif. Sehingga dibangunlah aplikasi ini supaya bisa mengatasi semua masalah yang terjadi dan menjadikan kinerja kantor SAMSAT menjadi lebih efektif dan menyajikan informasi biaya balik nama kendaraan melalui apliksai SMS Gateway.

Berdasarkan UU No. 28 Tahun 2009 Bea Balik Nama Kendaraan Bermotor (BBNKB) adalah pajak atas penyerahan hak milik kendaraan sebagai akibat perjanjian dua pihak atau perbuatan sepihak atau keadaan yang terjadi karena jual beli, tukar menukar, hibah, warisan, atau pemasukan ke dalam badan usaha [2]. Faktor penting yang dapat membantu meningkatkan efektivitas penerimaan BBNKB yaitu kualitas pelayanan publik yang baik, kompetensi sumber daya manusia (SDM) aparatur yang berkompeten dibidang perpajakan sehingga kesadaran wajib pajak akan pentingnya membayar pajak terus meningkat. Melalui pelayanan publik, dengan didukung oleh kompetensi sumber daya manusia aparatur pajak untuk memenuhi kewajibannya membayar pajak merupakan hal yang penting dalam penerimaan pajak BBNKB [3].

Dari penelitian terdahulu dinyatakan bahwa hambatan yang dihadapi oleh BP2RD Sulawesi Utara yakni banyaknya masyarakat yang membeli ataupun menjual kendaraan bermotor merasa terbebani melakukan pembayaran pajak sesuai peraturan yang berlaku, karena sistem ini belum menggunakan SMS (Short Message Service) Gateway [4].

SMS merupakan salah satu produk teknologi dan telah menjadi salah satu media untuk mendapatkan informasi tanpa harus terikat tempat dan waktu [5]. SMS Gateway merupakan suatu aplikasi yang memanfaatkan fasilitas SMS yang digunakan untuk pengiriman data secara ringkas dan pendek yang memungkinkan seorang pengguna telepon selular mendapatkan informasi dari aplikasi tersebut [6]. Layanan Pesan Singkat (SMS) adalah salah satu yang paling populer mode komponen layanan komunikasi sistem komunikasi seluler, menggunakan protokol komunikasi standar yang memungkinkan pertukaran pesan teks pendek antara telepon rumah dan perangkat seluler [7]. MySQL merupakan Software RDBMS (server database) yang dapat mengelola database dengan sangat cepat dan dapat menampung data dalam jumlah yang sangat besar, dapat diakses oleh banyak User (multi-User), dan dapat melakukan suatu proses secara sinkron atau barengan (multi-threaded) [8]. Aplikasi ini dapat digunakan untuk wajib pajak mengetahui jumlah biaya balik nama kendaraan bermotor yang dapat meningkatkan efesiensi kerja pada kantor SAMSAT kota Padang.

Menurut penelitian terdahulu, Madundang (2014) dengan judul "Analisis Perhitungan Pajak Kendaraan Bermotor Dan Bea Balik Nama Kendaraan Bermotor di Kantor SAMSAT Bitung". Tujuan penelitiannya untuk mengetahui perhitungan penetapan pajak kendaraan bermotor dan bea balik nama kendaraan bermotor di kantor SAMSAT Bitung. Menggunakan metode penelitian kualitatif. Hasil penelitian menunjukkan perhitungan pajak kendaraan bermotor dan bea balik nama kendaraan bermotor di UPTD Kota Bitung sudah sesuai dengan standar pelayanan UPTD SAMSAT di seluruh Sulawesi Utara.

Mustika (2013) dengan judul "Analisis Kontribusi Pajak Kendaraan Bermotor dan Bea Balik Nama Kendaraan Bermotor Terhadap Pendapatan Asli Daerah Provinsi Jawa Tengah". Tujuan penelitian ini untuk mengetahui kontribusi pajak kendaraan bermotor dan bea balik nama kendaraan bermotor. Menggunakan metode kuantitatif dan metode kualitatif. Hasil penelitian menunjukkan kontribusi pajak kendaraan bermotor dan bea balik nama kendaraan bermotor yang penerimaan realisasinya selalu melebihi target yang dianggarkan [9]. Penelitian selanjutnya oleh Mulyawan dan Novia (2016) dengan judul "Aplikasi Pembayaran Pajak Kendaraan Bermotor Online Berbasis Web (Studi Kasus Di Samsat Soreang Kab. Bandung). Tujuan dari penelitian ini adalah membuat sebuah aplikasi perhitungan pajak 
kendaraan bermotor berbasis web secara online. Saat ini pengolahan datanya masih dilakukan secara manual yang menyebabkan beberapa permasalahan dan membutuhkan waktu yang lama dalam melakukan pembayaran oleh wajib pajak. Hasil dari penelitian ini adalah sebuah aplikasi berbasis web untuk pembayaran Pajak Kendaraan Bermotor [10].

Dari beberapa penelitian terdahulu, maka dapat dibandingkan bahwa penelitian yang penulis lakukan berbeda dengan penelitian sebelumnya. Dimana pada penelitian terdahulu tujuan penelitiannya hanya menganalisis perhitungan pajak kendaraan dan BBNKB serta aplikasi yang berbasis web. Sedangkan penulis melakukan pengembangan penelitian tentang BBNKB yang sebelumnya berbasis web, dan sekarang menggunakan SMS Gateway, untuk mengetahui biaya BBNKB sebelum melakukan proses transaksi BBNKB.

\section{Metode Penelitian}

Metode dalam pembuatan aplikasi sistem informasi BBNKB melalui SMS Gateway yaitu dengan menggunakan metodologi pembangunan software berbasis SDLC dengan metode XP (Extreme Programming). Extreme Programing merupakan sebuah model pengembangan perangkat lunak yang mencoba menyederhanakan berbagai tahapan dalam proses pengembangan tersebut sehingga menjadi lebih adaptif dan fleksibel [11]. Secara umum tahapan dari XP adalah analisis, desain, implementasi, dan pengujian, dan pada akhirnya merilis aplikasi software [12]. Metode ini digunakan untuk mengetahui proses biaya balik nama kendaraan bermotor di SAMSAT kota Padang.

Sumber data yang digunakan dalam penelitian ini adalah data primer yaitu data yang dikumpulkan langsung oleh peneliti. Data ini merupakan data utama dalam penelitian ini,biasanya berbentuk observasi langsung dengan pihak yang terkait. Data primer didapatkan dengan wawancara langsung dengan Kepala SAMSAT kota Padang.

Cara pengumpulan data yaitu mengambil data pada kantor SAMSAT kota Padang dan retribusi daerah serta melakukan wawancara pada salah satu kepala kantor tersebut. Tahapan kerja metode XP dapat dilihat pada Gambar 1.

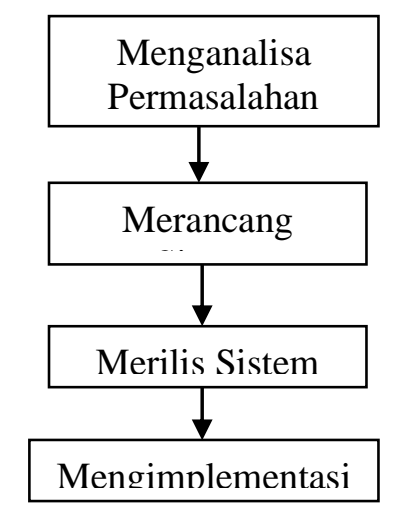

Gambar 1. Tahapan Kerja Metode XP

Extreme Programming (XP) merupakan suatu pendekatan yang paling banyak digunakan untuk pengembangan perangkat lunak cepat, yang prosesnya diawali dengan menganalisa masalah, merancang sistem, merilis sistem dan mengimplementasikannya.

\section{Hasil dan Pembahasan}

Perancangan sistem adalah tahapan setelah analisis dari siklus pengembangan sistem yang didefinisikan dari kebutuhan-kebutuhan fungsional dan persiapan untuk rancang bangun implementasi yang menggambarkan bagaimana suatu sistem dibentuk.

\subsection{Perancangan Sistem}

Penelitian ini menggunakan diagram Unified Modeling Language (UML). UML adalah salah satu standar bahasa yang banyak digunakan di dunia industri untuk mendefinisikan requirment, 
membuat analisis dan desain, serta menggambarkan arsitektur dalam pemrograman berorientasi objek [12]. Sistem perancangan menggunakan model unified proses seperti diagram use case, diagram skuense dan diagram kelas digambarkan sebagai berikut.

a. Use Case Diagram Sistem Pembayaran Pajak

Untuk use case diagram sistem pembayaran pajak di kantor SAMSAT Padang dapat dilihat pada Gambar 2.

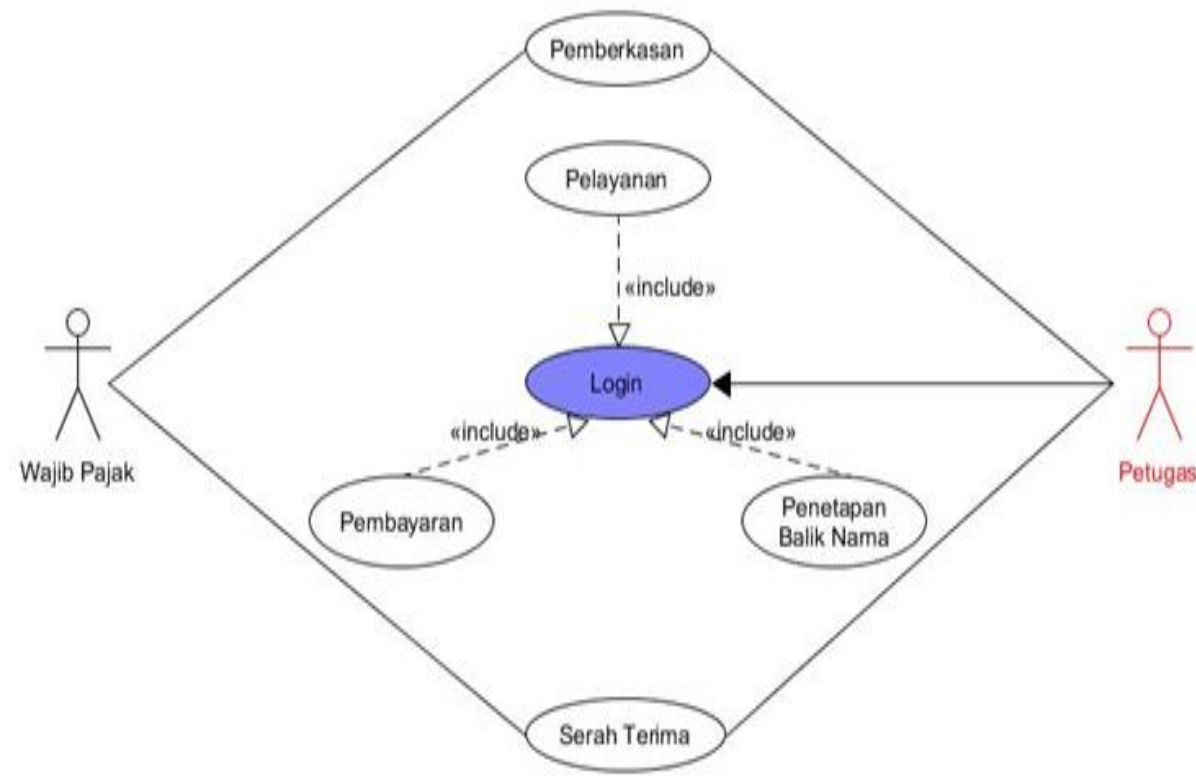

Gambar 2. Use Case Diagram Sistem Pembayaran Pajak

Dari Gambar 2. dapat dilihat bahwa wajib langsung datang ke kantor SAMSAT untuk menyerahkan berkas saat melakukan transaksi pajak atau balik nama, tanpa adanya media informasi petunjuk biaya balik nama yang akan mereka bayar. Saat melakukan pembayaran lahah para pajak akan mengetahui biaya balik nama yang akan mereka bayar.

b. Use Case diagram admin

Pada use case diagram admin, yang menjadi actor utamanya adalah admin. Untuk lebih jelasnya dapat dilihat pada tampilan Gambar 3.

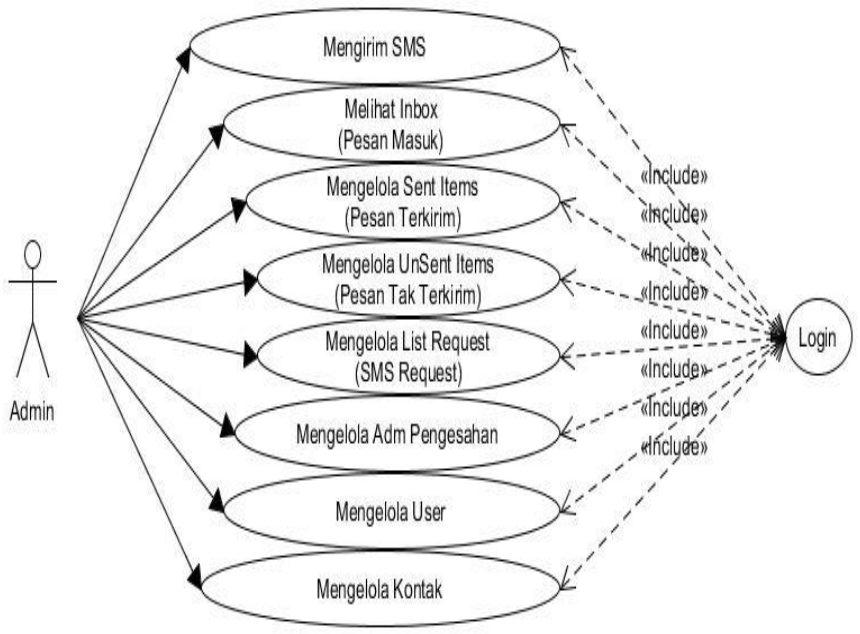

Gambar 3. Use Case Diagram Admin 
Pada Gambar 3, Use case diagram admin menggambarkan bahwa admin menginformasikan BBNKB melalui SMS Gateway dan menampilkan apa yang bisa di lakukan oleh aktor terhadap sistem yang akan dibangun. Disini aktor tersebut adalah admin, petugas dan wajib pajak. Admin dan petugas memiliki peran yang hampir sama terhadap sistem, yang membedakannya petugas tidak bisa mengelola user dan mengelola adm pengesahan. Peran admin dalam use case di atas yaitu mengirim sms, melihat pesan masuk, mengelola pesan terkirim, mengelola pesan tidak terkirim, mengelola list request, mengelola adm pengesahan, mengelola user, dan mengelola kontak.

c. Use Case Diagram Wajib Pajak

Untuk aktor wajib pajak, perannya dapat dilihat pada use case diagram wajib pajak seperti tampilan pada Gambar 4.

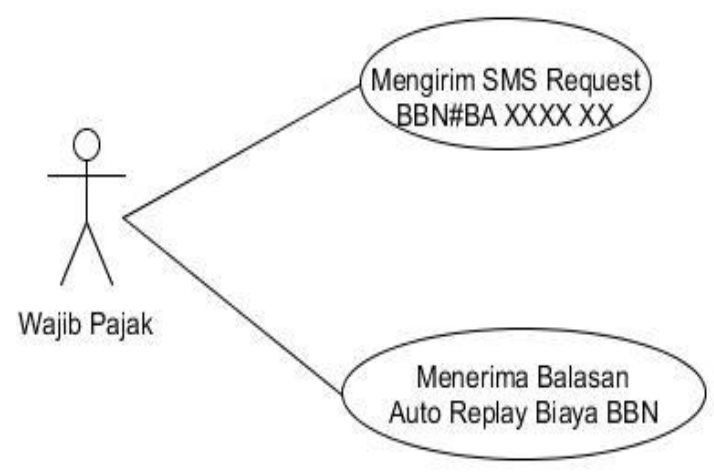

Gambar 4. Use Case Diagram Wajib Pajak

Pada Gambar 4, wajib pajak mengirim sms dengan format bbn\#Nomor polisi seperti contoh bbn\#ba $1234 \mathrm{xx}$ dan jika format benar akan menerima sms balasan nantinya yang memberitahukan jumlah biaya balik nama kendaraan.

d. Class Diagram

Untuk class diagram sistem informasi biaya balik nama kendaraan bermotor melalui SMS gateway dapat di tunjukkan pada Gambar 5.

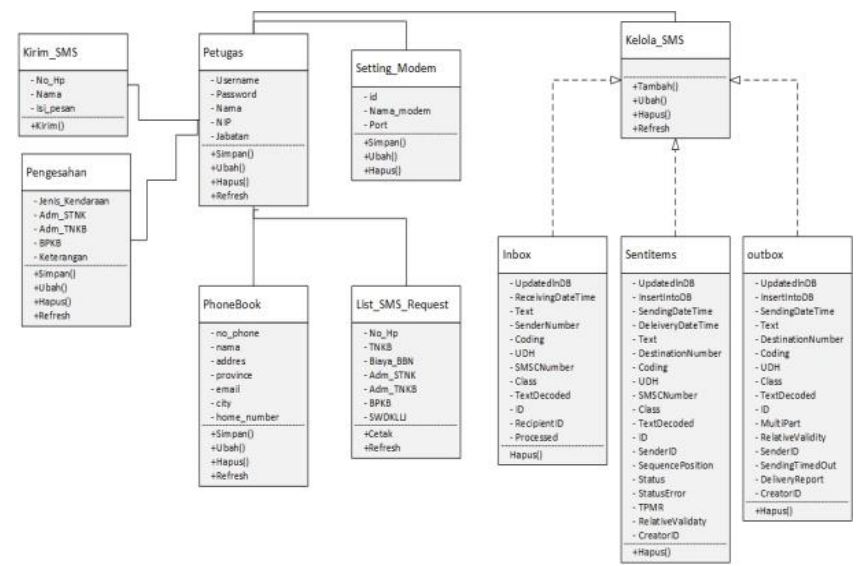

Gambar 5. Class Diagram

Class Diagram di atas terdapat beberapa class sistem yang dirancang, diantaranya Petugas, Kirim SMS, PhoneBook, Kelola SMS (Inbox, Outbox dan SentItems), List SMS Request, Pengesahan dan Seting Modem. Dalam tiap class terdapat beberapa elemen dari class-class tersebut, sehingga elemen-elemen tersebut bisa dilakukan perubahan seperti simpan, tambah, ubah dan hapus. 


\subsection{Implementasi Program} berikut ini.

Hasil dari perancangan sistem yang dibuat dapat dilihat pada implementasi program

a). Form Login.

Admin atau petugas dapat mengakses halaman admin atau petugas dengan Login terlebih dahulu pada form Login pada Gambar 6.

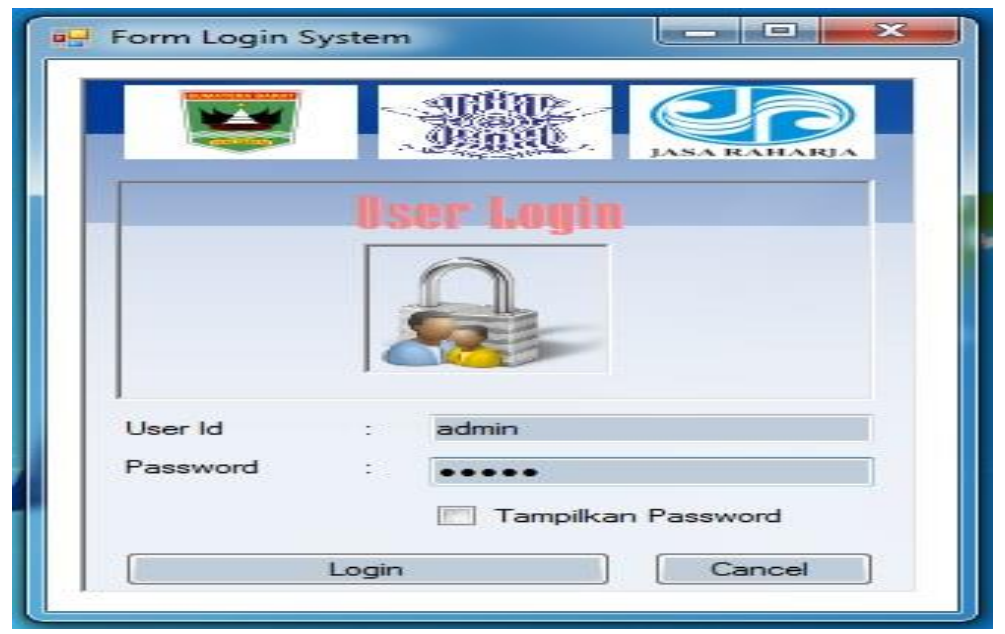

Gambar 6. Form Login

Pada Form login di atas, sebelum masuk, admin diharuskan untuk mengisi User Id dan passwordnya, setelah itu admin dapat memilih Login untuk masuk ke sistem.

b). Halaman Utama

Setelah login, maka kita masuk ke halaman utama, seperti pada Gambar 7.

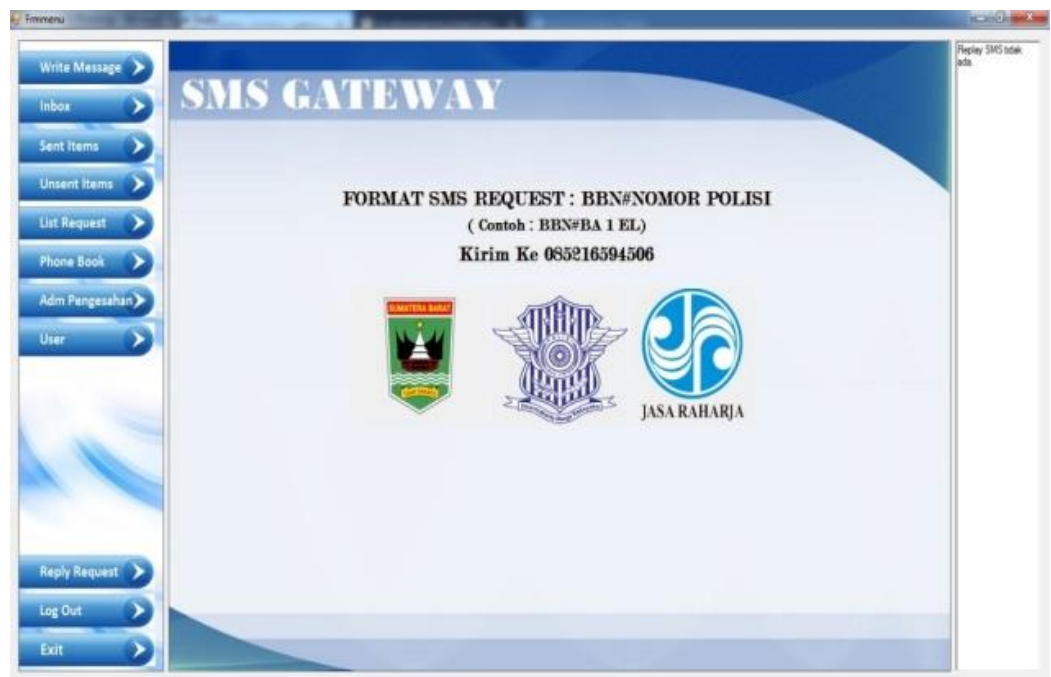

Gambar 7. Halaman Utama

Pada Gambar 7 terdapat beberapa menu untuk menampilkan keseluruhan sub-sub menu yang akan dieksekusi dalam menu utama.

c). Form Entry User

Menu ini digunakan untuk memanipulasi data User pada database. Setiap data User akan ada penanda apakah User tersebut seorang admin atau bukan dari jabatannya. 
Jika jabatan administrator maka User tersbut adalah admin dapat dilihat pada Gambar 8.

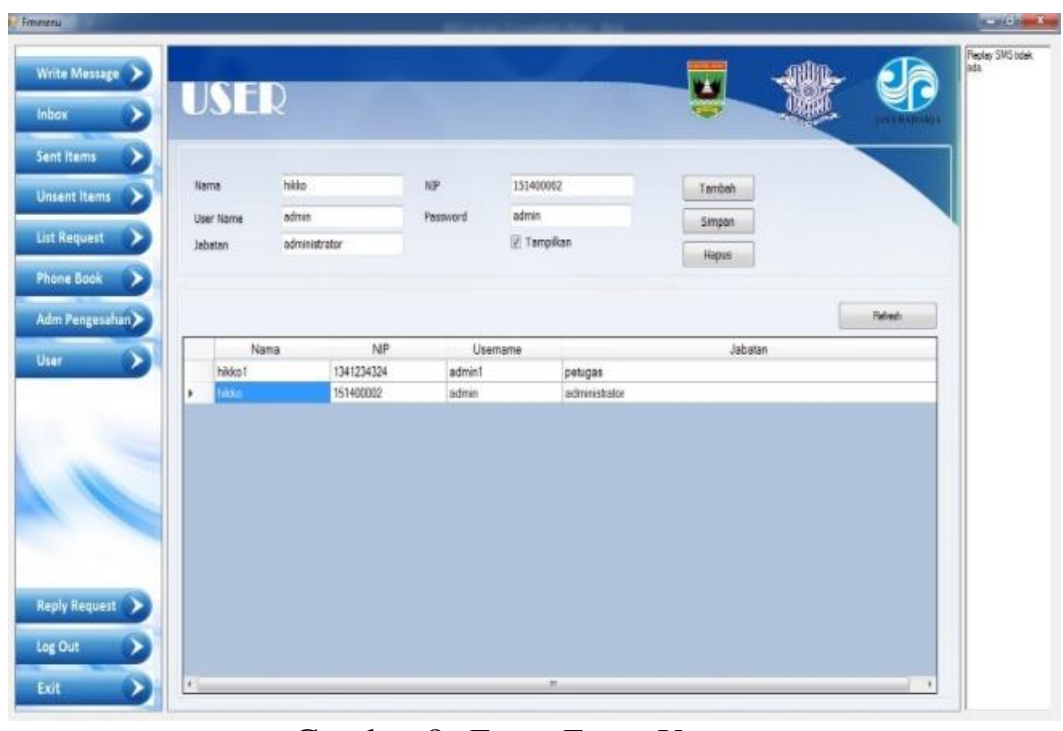

Gambar 8. Form Entry User

Pada Gambar 8 terdapat beberapa yang harus diinput, yaitu nama, username, jabatan, nip, dan password. Ada tiga tombol yaitu tombol simpan, tambah dan hapus, masing-masing tombol tersebut berfungsi.

d). Form Entry Adm Pengesahan

Form entry Adm Pengesahan terdapat beberapa data yang harus diisi seperti terlihat pada Gambar 9.

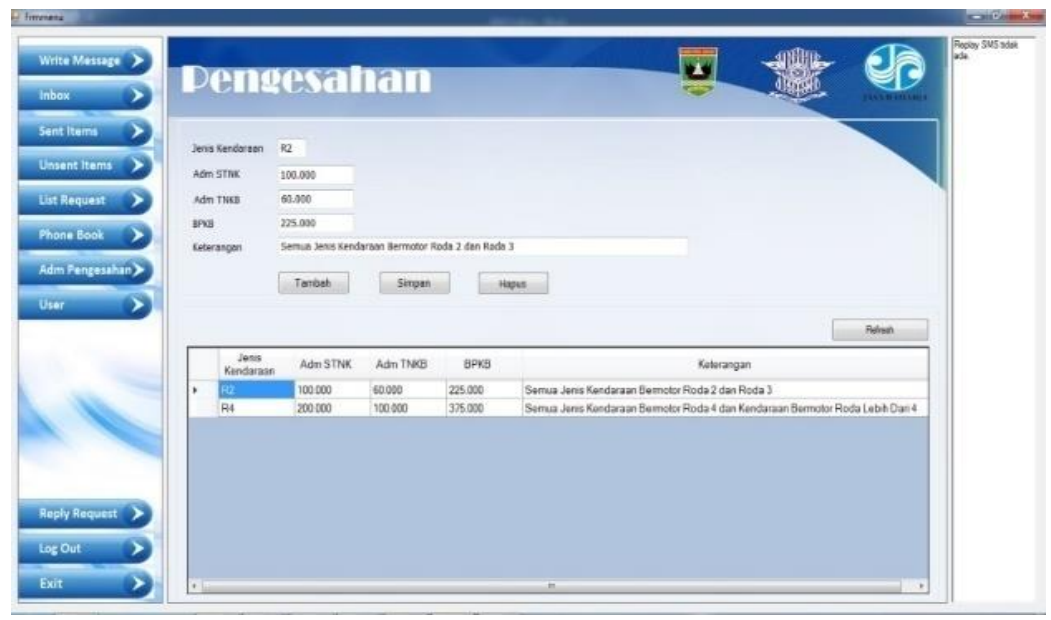

Gambar 9. Form Entry Adm Pengesahan

Menu ini digunakan untuk memanipulasi data Adm Pengesahan pada database. Setiap Adm Pengesahan akan diberi Jenis Kendaraan berdasarkan jenisnya apakah roda 2 dan 3 atau roda 4 dan di atasnya, dimana memiliki nilai adm yang berbeda. Admin juga bisa melakukan edit data atau menghapus data adm pengesahan tersebut

e). Form Input Buku Telepon

Form input buku telepon akan diisi data-data yang sesuai pada form pada Gambar 10. 


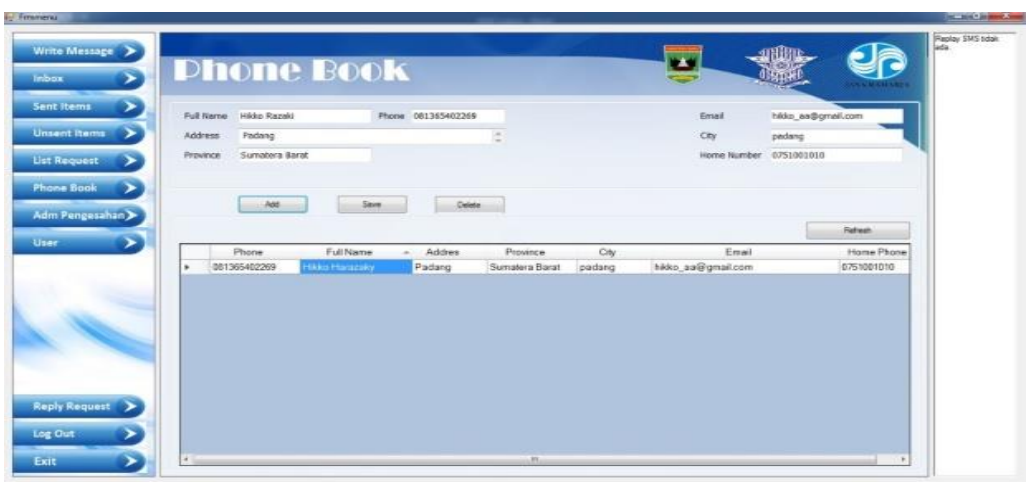

Gambar 9. Form Buku Telepon

Menu di atas digunakan untuk memanipulasi data buku telepon pada database. Setiap phonebook akan memiliki phone yang berbeda sesuai nama. Admin juga bisa melakukan edit data atau menghapus data buku telepon tersebut.

f). Form Tulis Pesan

Form tulis pesan diisi sesuai data seperti pada Gambar 11.

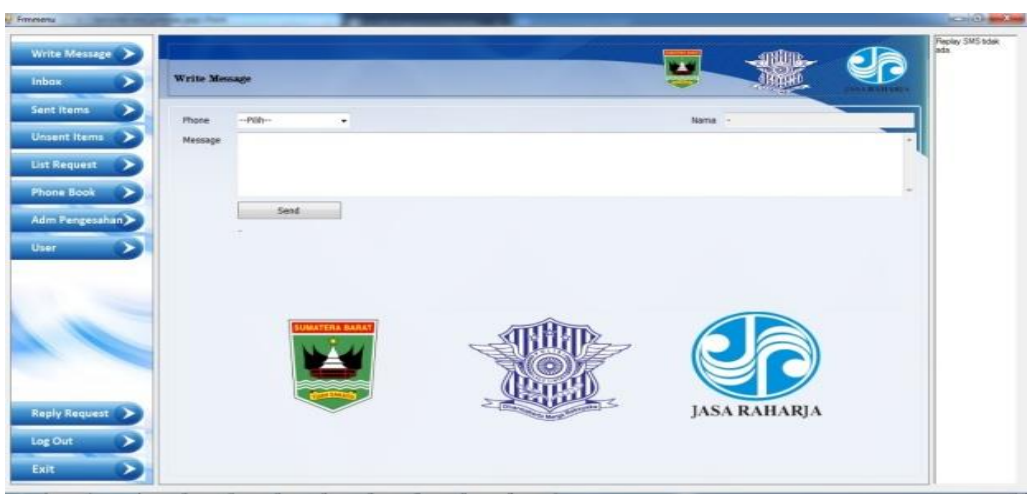

Gambar 10. Tampilan Tulis Pesan

Menu diatas untuk menulis dan mengirim sms seperti layaknya di lakukan pada ponsel selular. Pada pemilihan nomor telpon bisa pilih dari buku telepon yang telah tersimpan atau diinput manual.

g). Tampilan Pengaturan Modem

Untuk tampilan pengaturan modem dapat dilihat seperti Gambar 12.

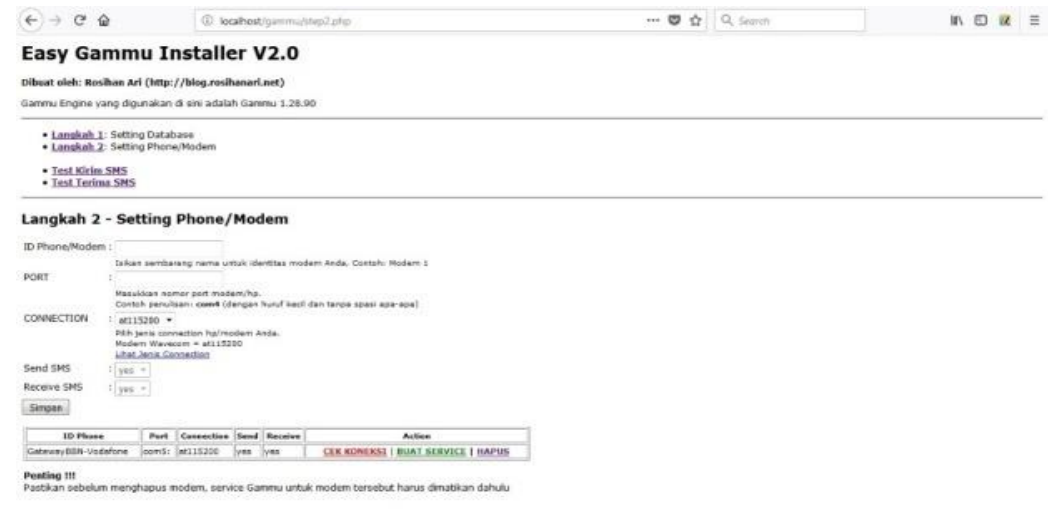

Gambar 12. Form Pengaturan Modem 
Menu ini digunakan untuk mengatur settingan modem supaya terkoneksi dan aplikasi bisa mengirim balas otomatis balasan dan menerima pesan permintaan

h). Menu Pesan masuk

Menu pesan masuk dapat dilihat seperti pada Gambar 13.

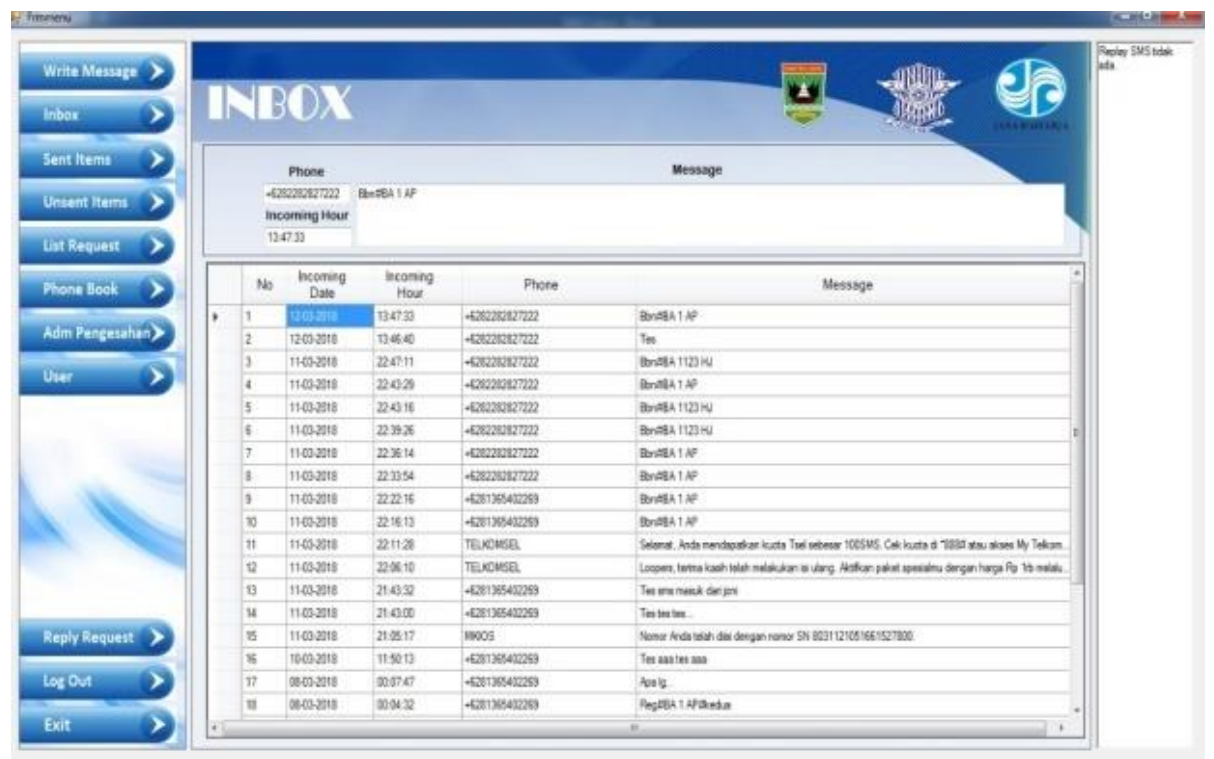

Gambar 13. Menu Pesan Masuk

Gambar 13 menampilkan pesan masuk dari sms yang dikirim oleh pengirim pesan dan sms permintaan wajib pajak.

i). Menu Pesan Terkirim

Menampilkan pesan-pesan terkirim dari sistem yang dapat dilihat pada Gambar 14.

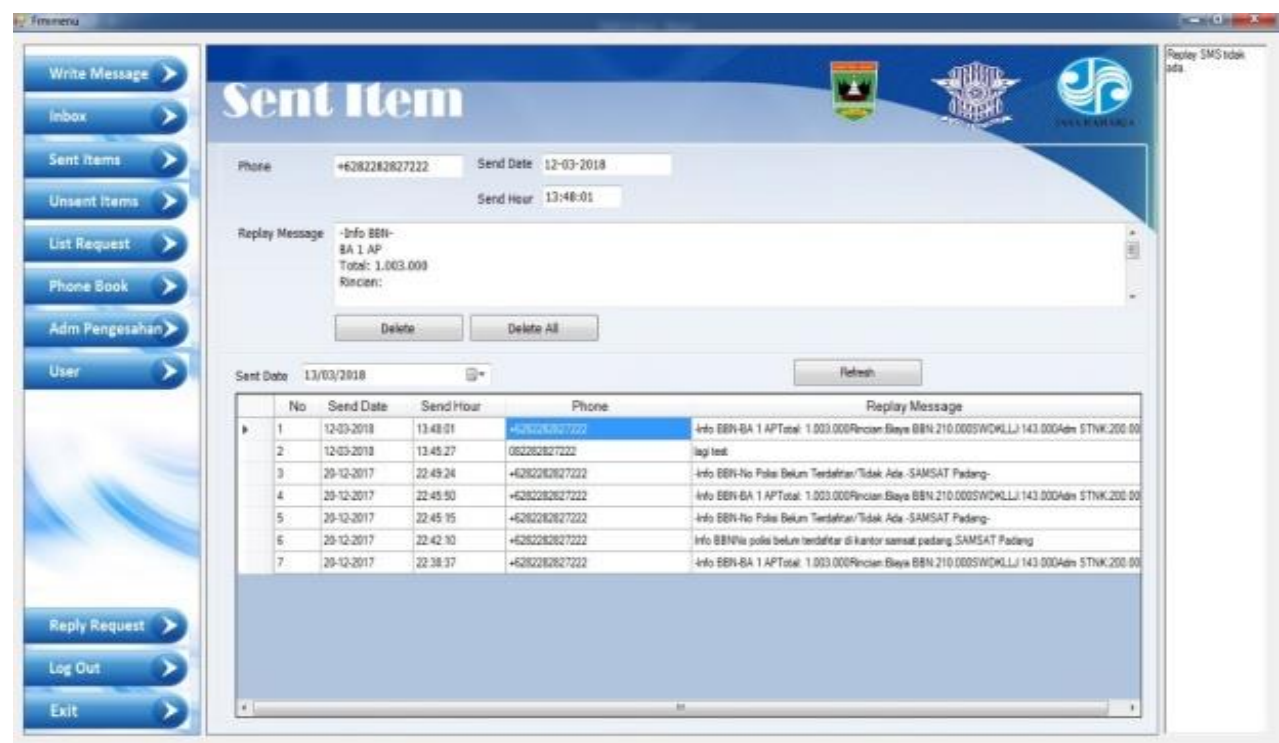

Gambar 14. Menu Pesan Terkirim

Gambar 14 menunjukkan menu pesan terkirim yang dibalas secara otomatis oleh sistem. Menu ini dapat dijadikan sebagai laporan.

j). Menu Pengguna

Menu pengguna dapat ditampilkan seperti Gambar 15. 


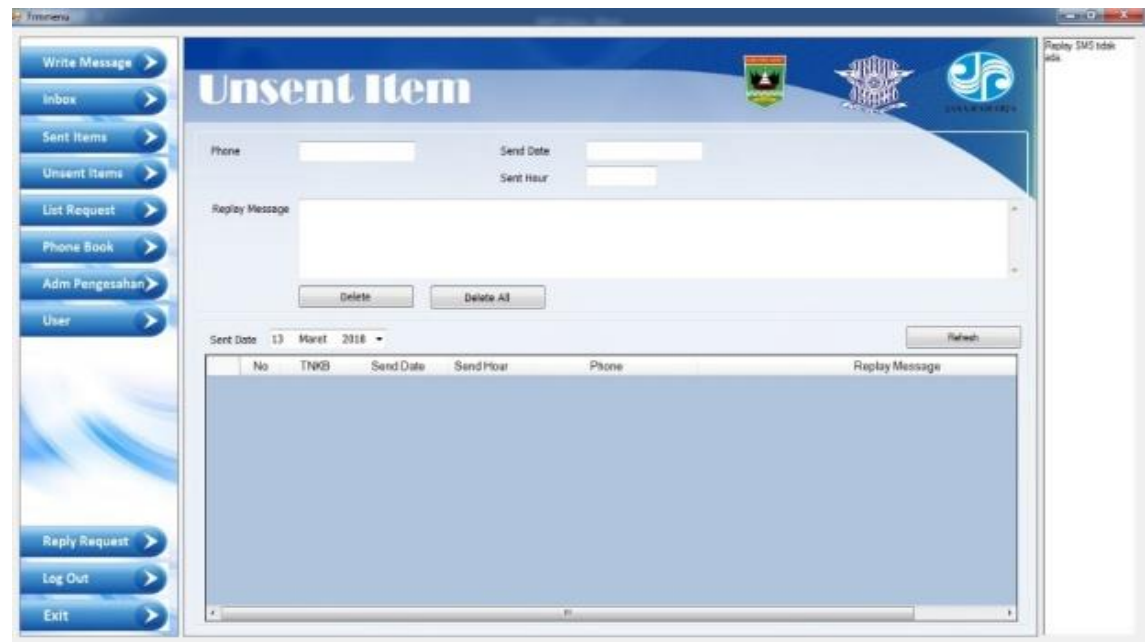

Gambar 15. Menu Pengguna

Gambar 15 menampilkan pesan-pesan tidak terkirim yang dibalas otomatis oleh sistem. Terjadi apabila nomor penerima tidak aktif atau pulsa modem habis. Pesan otomatis yang akan mengirim ulang kembali secara manual pesan-pesan tak terkirim tersebut.

k). Menu Data Permintaan

Menu ini merupakan tampilan semua pesan secara otomatis dari sms permintaan yang dilakukan wajib pajak dan berhasil terkirim ke wajib pajak tersebut. Admin atau petugas bisa melakukan cetak laporan data permintaan jika diperlukan oleh pimpinan seperti Gambar 16.

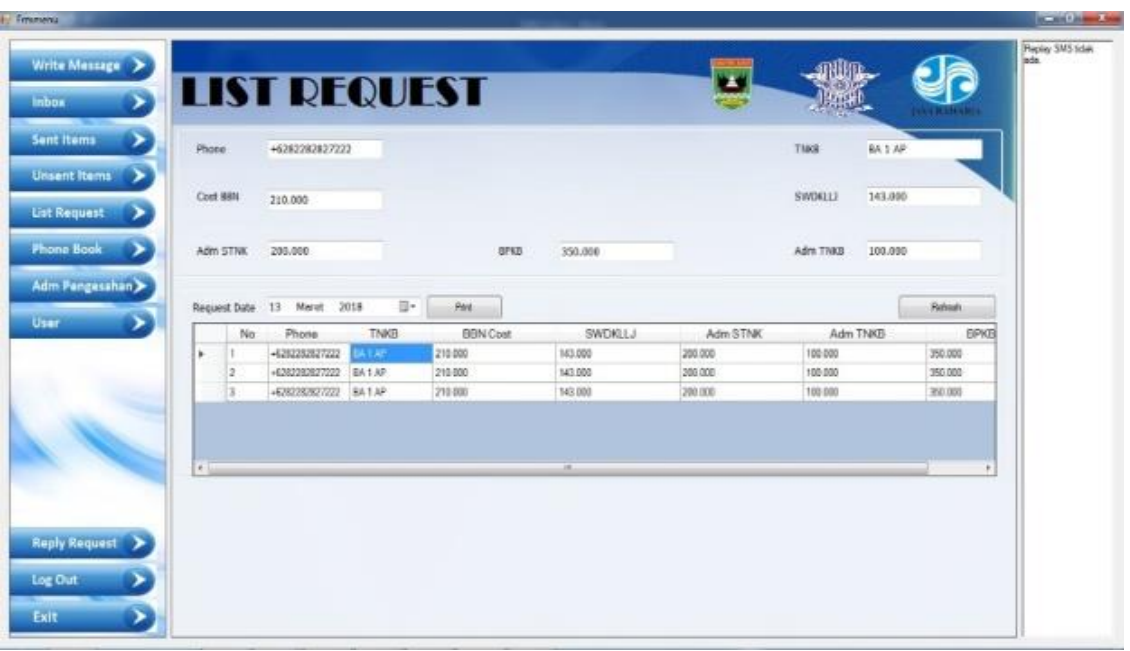

Gambar 16. Menu Data Permintaan

Gambar 16 menampilkan data permintaan dari wajib pajak. Apabila tidak terkirim, maka akan di balas otomatis oleh sistem berupa Auto Replay dan pesan terkirim pada write message. Hal ini terjadi apabila nomor penerima tidak aktif atau pulsa modem habis. Button Reply Request lah yang akan mengirim ulang kembali secara manual pesan-pesan tak terkirim tersebut.

1). Laporan Data Permintaan

Menu ini merupakan tampilan laporan harian SMS Permintaan yang terkirim seperti Gambar 17. 


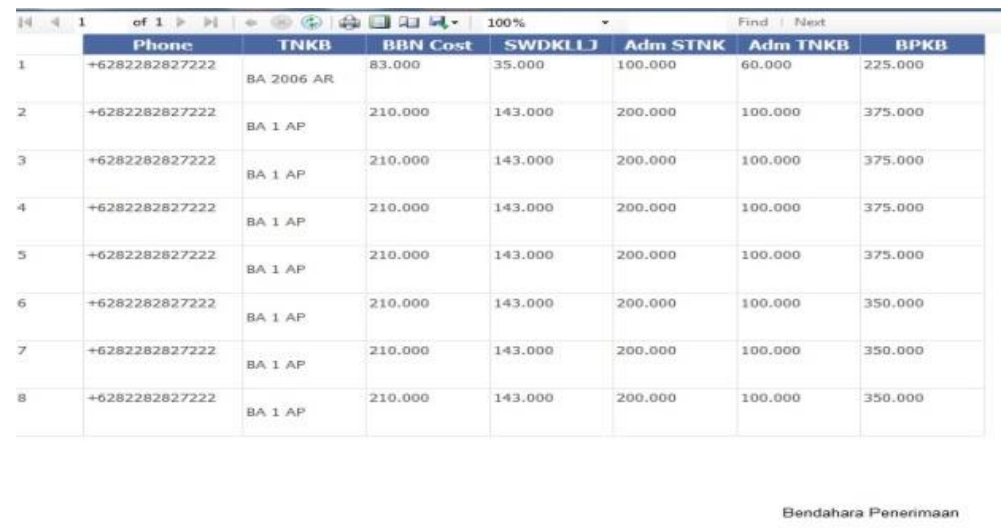

VALWINA WIDHIA, SE
19691223 1990022001

Gambar 17. Laporan Data Permintaan

Gambar 17 merupakan laporan semua data permintaan dari wajib pajak untuk mendapatkan laporan biaya balik nama kendaraan bermotor. Laporan data permintaan ini nantinya akan diberikan kepada pimpinan sebagai laporan data.

13). Untuk format tampilan balasan SMS permintaan dapat dilihat pada Gambar 18.

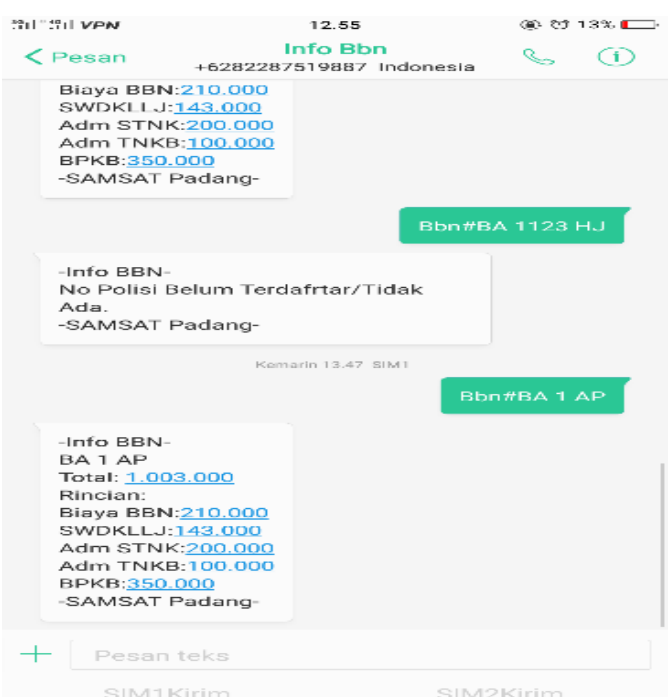

Gambar 18. Tampilan Balasan SMS Permintaan

Pada Gambar 18, dijelaskan bahwa apabila format SMS Permintaan yang dikirim oleh wajib pajak benar dan nomor polisi terdaftar dikantor SAMSAT, maka sistem akan membalas otomatis dengan berisikan informasi biaya balik nama yang akan di bayarkan. Tapi jika nomor polisi tidak terdaftar maka akan muncul pemberitahuan nomor polisi tidak terdaftar.

\section{Kesimpulan}

Dari analisa dan pembahasan yang telah dilakukan pada bab-bab sebelumnya, maka dapat diambil beberapa kesimpulan sebagai berikut:

1. Hasil dari penelitian ini berupa aplikasi BBNKB yang merupakan sarana untuk memberikan informasi biaya balik nama kendaraan bermotor sebelum melakukan transaksi balik nama melalui SMS Gateway. 
2. Dengan adanya aplikasi BBNKB ini, dapat meningkatkan pelayanan publik dan efektifitas kinerja di kantor SAMSAT Kota Padang.

3. Aplikasi BBNKB ini dapat mengurangi permasalahan yang terjadi pada saat melakukan transaksi balik nama kendaraan bermotor, karena pelanggan dapat mengetahui biaya BBKNB melalui SMS Gateway.

\section{Ucapan Terima Kasih}

Ucapan terima kasih penulis ucapkan kepada STMIK Indonesia Padang dengan Nomor Kontrak: 015/K.A/LPPM STMIK-I/2018 yang telah mendukung dan mendanai penelitian ini, dan pihak-pihak yang terkait yang telah memberikan dukungan terhadap penelitian ini.

\section{Daftar Pustaka}

[1] D. I. Kantor, B. Samsat, F. Ekonomi, and J. Akuntansi, "Analisis Perhitungan Pajak Kendaraan Bermotor Dan Bea Balik Nama Di Kantor Bersama Samsat Bitung", vol. 2, no. 4, pp. 90-99, 2014.

[2] S. Mdp and J. R. No, "Analisis Kontribusi Pajak Kendaraan Bermotor Pajak Bea Balik Nama Kendaraan Bermotor Dan Pajak Bahan Bakar Kendaraan Bermotor Terhadap Pendapatan Asli Daerah Provinsi Sumatera Selatan,” Pp. 1-12, 2017.

[3] E. Yurikadatuyahoocom, "Aplikasi Pajak Kendaraan Bermotor Berbasis SMS Gateway," vol. 8, no. 1, pp. 2-7, 2016.

[4] U. S. Ratulangi, "Analisis Penerimaan Pajak Bea Balik Nama Kendaraan Bermotor DiSulawesi Utara," vol. 13, no. 3, pp. 303-310, 2018.

[5] D. M. B and A. M. Bakti, "Implementasi Dan Pengujian Sms Gateway Sebagai Media Alert Warning Jatuh Tempo Pajak Kendaraan Bermotor," no. 12, pp. 1-11, 2012.

[6] muhammad taufiq muslih, "Pengembangan aplikasi SMS Gateway untuk informasi pendaftaran peserta didik baru di SMA N 1 Jepara," J. Sist. Inf., vol. 2, 2013.

[7] A. Maiti and B. K. Tripathy, "Applications of Short Message Service and WAP in Operating Remotely Triggered Laboratories," vol. 7 No.4, pp. 20-25, 2011.

[8] Anisya, "Aplikasi sistem database rumah sakit terpusat pada rumah sakit umum (RSU) Aisyah padang dengan menerapkan open source (PHP-MYSQL)," J. momentum, vol. 15, 2013.

[9] Mustika, "Analisis Kontribusi Pajak Kendaraan Bermotor dan Bea Balik Nama Kendaraan Bermotor Terhadap Pendapatan Asli Daerah Provinsi Jawa Tengah, jurnal udinus, 2013.

[10] S. M. Indonesia, "Aplikasi Pembayaran Pajak Kendaraan Bermotor Online Berbasis Web ( Studi Kasus Di Samsat Soreang Kab . Bandung ),” vol. 10, no. 1, pp. 30-39, 2016.

[11] M. A.S.,Rosa dan Shalahuddin, "Rekayasa Perangkat Lunak terstruktur dan berorientasi objek," 2013.

[12] Rosa, "Rekayasa Perangkat Lunak," 2015.

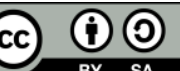

Y Digital Zone: Jurnal teknologi informasi dan Komunikasi is licensed under a_Creative Commons Attribution International (CC BY-SA 4.0) 